\title{
Entrepreneurs As Parents: The Antecedents and Consequence of Parenting Stress
}

\author{
Anil Boz Semerci \& Thierry Volery \\ International Journal of Entrepreneurial Behavior \& Research
}

\begin{abstract}
Purpose - This study aims to understand parenting stress of entrepreneurs and attempts to extend the empirical evidence on the predictors and consequences of parenting stress for entrepreneurs.

Design/methodology/approach - This study draws on data from the Household, Income and Labour Dynamics in Australia (HILDA) survey. The sample comprises of 2051 entrepreneurs with parenting responsibilities. The antecedents and consequences of parenting stress are tested using structural equation modelling.

Findings - The results reveal that social support is a strong predictor of parenting stress and that there is a direct effect between parenting stress and family to work interference (FWI). In addition, parenting stress partially mediates the relationship between social support and FWI. Adding a direct path from social support to FWI substantially improves the validity in a revised model. No effects of gender stereotypes are found.

Originality/value - This study attempts to extend previous work on parenting and vocational behaviour by investigating the perceptional and stereotypical antecedents of parenting stress and examining the impact of parenting stress on family to work interference. In addition to the challenges of parenting, many entrepreneurs face constant pressure to achieve a positive return in their business venture and work for long hours. A better understanding of entrepreneurs' parenting roles and stress contributes to the vocational behaviour literature and the achievement of work-life balance for entrepreneurs.
\end{abstract}


Key Words - Entrepreneurs, parenting stress, social support, stereotypes, family to work interference

\section{Paper type - Research Paper}

\section{Introduction}

The composition of the workplace has changed significantly over the past decades. As the number of dual-career couples and single-parent households has steadily risen, media and research has increasingly focused on balancing the competing and often overwhelming demands of work and family commitments (Eby et al., 2005). Management, organizational behaviour, psychology and sociology scholars have long recognized that family life plays a key role in explaining the individuals' professional experience (Erickson et al., 2000; Loscocco, 1997; ten Brummelhuis et al., 2010). At the same time, combining work responsibilities with family demands proves a challenge for a lot of working parents (Cuddy et al., 2004). This situation is likely to induce parenting stress (Deater-Deckard, 2005; Koeske and Daimon Koeske, 1990).

Entrepreneurship has often been touted as a viable option to strike a balance between work demands and family roles (McGowan et al., 2012). The high autonomy associated with this career option allows individuals to work on a flexible schedule and often at a location of their choice, which should allow them to spend more time on childcare responsibilities (Boden, 1996; Thompson and Prottas, 2006). In addition, entrepreneurship holds the promise that an individuals' career success will depend on their own merits. As such, it is viewed as an attractive career path by some women and people from minority groups who often face the preconceptions and prejudices of others in the work setting (Heilman and Chen, 2003).

While the effects of work-family conflict has been studied in corporate settings (Benjamin and Samson, 2014; ten Brummelhuis et al., 2010), the examination of parenting stress that entrepreneurs face and its influence on their work is limited and the results are inconclusive. One stream of research suggests that, by "being their own boss", entrepreneurs can better balance work and family demands, resulting in a decrease of parenting stress (Boden, 1996; Lombard, 2001). However, another stream of research suggests that entrepreneurship has no positive effect on parenting stress and that the inherent pressure of running a business venture, 
including long working long hours and financial risks increase the total array of pressures (Kirkwood and Tootell, 2008; Stoner et al., 1990).

In addition, much of the research on the determinants and consequences of parenting stress focused thus far on children-based issues including disability or hyperactivity (Hastings, 2002; Johnston and Mash, 2001), parent-child attachment (Louie and Cromer, 2014) and child abuse (McPherson et al., 2008). There is a need to examine predictors from the wider social context and, concurrently, to investigate the effects of parenting stress on work life.

The objective of the present study is to examine the antecedents and consequences of parenting stress for entrepreneurs. Moving beyond children-based issues, this research investigates the influence of social support and gender stereotypes on parenting stress and the impact of parenting stress on family to work interference (FWI). The influence of family variables on work decisions (rather the influence of work variables on family) was examined because, as management scholars, we are more interested on vocational behaviour as an outcome.

\section{Literature Review and Hypothesis Development}

The first theoretical anchor for this study is conservation of resource theory (COR) originally developed by Hobfoll (1989). This resource-oriented approach posits that people strive to retain, protect, and build resources and that what is threatening to them is the potential or actual loss of these valued resources. Resources are defined as objects (e.g. car, house), conditions (e.g. marriage, job security), personal characteristics (e.g. resilience, self-efficacy) and energies (e.g. money, time, knowledge). When these resources are threatened or lost, people experience stress. In a subsequent study, Hobfoll et al. (2002) found that those endowed with greater, or in some way richer, social support are able to preserve physical and psychological health in the face of stressors and overall through their lifetime. In the present study, consistently with COR theory, we consider social support and gender stereotypes as two resources which have respectively a positive and negative impact on entrepreneurs' parenting stress.

The second theoretical background for this research is Eagly's (1997) social role theory, which suggests that sex differences arise from contrasting distributions of women and men into social roles. As society and social norms help to create and maintain these social roles, women and men seek to adjust to the roles available for them and develop special skills related to these 
roles. Typically, men are more likely to fulfil roles outside the home and be the main breadwinner, whereas women are generally responsible for child rearing and other domestic tasks such as cooking. In this context, gender roles facilitate the activities typically carried by people of each sex and gender-stereotypic expectations can also affected behaviour by becoming internalised as part of individuals' self-perception and personalities (Eagly et al., 2000). Therefore, in this study the antecedents and consequence of parenting stress are analysed by distinguishing between men and women entrepreneurs. By this means, the impact on parenting stress can be explained from a gender-specific perspective.

\section{The antecedents of parenting stress}

Having a child and becoming a parent is likely to be the most permanent and crucial decision in a person's life. Parenting has never been an easy task, but changes away from traditional patterns of family organization, as reflected by the increasing number of single parents and dualwage couples, put additional pressure on families (Hetherington, 2014; Locke and Yarwood, 2017; Thomason et al., 2014). While parents have always had to deal with various stressors, such as managing their child's emotions or their negative perceptions toward them, the peculiarities of the post-modern context make raising children with positive self-esteem and core values a more daunting task than in the past. Fast-paced lifestyles, a competitive economy and rampant consumerism pose increasing challenges and stress for parents. In this context, parenting stress can be defined as the issues of parent-child interactions and refers to "a condition or feeling experienced when a parent perceives that the demands associated with parenting exceed the personal and social resources available to meet those demands" (Cooper et al., 2009, p. 559).

In previous studies that considered multivariate models, social support has been also identified as a central coping resource to deal with parenting stress (Raikes and Thompson, 2005; ten Brummelhuis et al., 2012). Cobb (1976, p. 300) defined social support as "the individuals' perceptions that he or she is cared for, loved, valued and beliefs of the existence and availability

of people on whom he or she can rely on". This concept corresponds to the degree of an individual's feelings of belonging to a network of communication and mutual obligation. Consequently, social support draws on multiple aspects of social capital such as the size and strength of a person's social network, the types of social support offered (instrumental, 
informational, emotional or appraisal), and the perception of support (Canty-Mitchell and Zimet, 2000). In this study, the focus is on parents' perceived social support. Focusing on the subjective dimension, this type of social support is the perceived provisions supplied by the social network and confiding partners (Pierce et al., 2013).

Social support has been associated with different important outcomes such as mental health, mortality, physical health, recovery from illness and the capacity to withstand stress (Wallace, 2014). It helps people to share a wide range of issues with others, to obtain empathy and to try out new perspectives and ideas. This enables the person to cope with and adjust to difficult and stressful events (Berkman et al., 2000; Lin et al., 2013). The availability and accessibility of social support are crucial ingredients in the adaptive response to the demands of parenting, and defend individuals from the negative effects of parenting stressors. This support can be found in family relationships, in friendships, in neighbourhood or community contacts (Bokhorst et al., 2010; Piko, 2000).

Past studies found that parenting stress is lower for parents who have more perceived support from their partners, family members, and friends (Ostberg and Hagekull, 2000). Powell (1980) reported that mothers' responsiveness to parenting demands are much better for those who had at least weekly contact with friends. Moreover, parents who have high social support are more willing to adjust childrearing practices to match the child's developmental capabilities (Huang et al., 2014; Taylor et al., 2015).

The importance of social support has also been discussed within the entrepreneurship context. Davidson, et al., (2010) demonstrated that social support is a key resource for entrepreneurs to cope with stressful situations. Similarly, Zhu et al., (2017) found that support from families decreases the challenge and hindrance appraisals of entrepreneurs, which in turn, decrease their venture exit intention. In sum, social support acts as a buffer that protects individuals from the harmful effects of stress associated with their roles. Thus,

$\mathrm{H}_{1}$ : Social support will be negatively related with parenting stress for both female and male entrepreneurs.

Despite the increasing number of dual-income families, role conflicts and gender stereotypes remain an important source of work-family conflicts (Heilman, 2001). Gender stereotypes are 
shared beliefs about the characteristics, attributes and behaviours of members associated with members of each sex (Powell and Graves, 2003). While sex is a term related to biology, anatomy and hormones, gender refers to the social, cultural, and psychological implications of being male or female (Ahl, 2006). In gendered-stereotyping, individuals categorize people according to their sex and then develop beliefs about the attributes and behaviours such as characteristics, occupations and family roles of the members of these groups (Powell et al., 2002).

Gender stereotypes are socially constructed learned ideas that tend to remain stable over time in different cultures (Hamilton and Sherman, 2014). These are often learned in childhood and adolescence, and are facilitated by parents, teachers, peers and the mass media (Gupta et al., 2009). Tull et al., (2005) found that stereotypes are often "internalized" and have a significant relationship with perceived psychological distress. Lindsey (2015) also remarked that, as a result of gendered socialization, men and women develop different identities that are the internalization of expected responsibilities and roles in work and family domains. These identities make them more sensitive and vulnerable to demands in various domains of life.

In this study, gender stereotypes encompass conservative beliefs about the working and parenting roles of women. The view that housework and raising children rests primarily with women, and that this role requires total investment, is likely to generate higher parenting stress for women who internalize such beliefs. According to this view, men are the breadwinners and may have an assistance role in parenting, but no main responsibilities, and are therefore likely to exhibit lower parenting stress. Overall, the persistence of stereotypes makes motherhood and caregiver roles less negotiable, compared to fatherhood; whilst at the same time, society expects women to fulfil a more diverse range of roles (Grönlund, 2007). Therefore,

$\mathrm{H}_{2 \mathrm{a}}$ : Traditional gender stereotypes will increase parenting stress.

$\mathrm{H}_{2 b}$ : The relationship between traditional gender stereotypes and parenting stress will be significantly different between female and male entrepreneurs.

\section{The consequence of parenting stress}

Personal resources such as time, energy and money need to be allocated successfully between family and work, which are the two main domains in individuals' lives (Peeters et al., 2005). 
Parenthood is the key aspect of family life and parenting demand requires sustained physical and mental personal resources. Since personal resources are limited, the resources spent on family tasks cannot be spent on work and vice versa (Benjamin and Samson, 2014). Given the increasing prevalence of dual-breadwinner families, single working parents and the growing pressure in the workplace, negative spillover between work and family domains is becoming more acute (Shimazu et al., 2009; Walsh, 2013).

Since the concept of work-family conflict was introduced, a large body of literature has examined the impact between the work and family domains through two distinct, albeit related concepts: work to family interference (WFI) and family to work interference (FWI). There is strong support for distinguishing between these two concepts and working on causes and effects separately. For example, Kelloway et al., (1999) found that work factors relate more strongly to work interfering with family, and some non-work factors were to family interfering with work. Mesmer-Magnus and Viswesvaran (2005) also reported consisted support for distinguishing between the directions of work-family conflict.

Family to work interference occurs when demands of the family hinder performance at work (Frone et al., 1992). The parenting stress as a non-work factor influences FWI in different ways. First, the difficulties in meeting the parenting demands may drain personal resources and lead the tension in work life for both men and women (ten Brummelhuis et al., 2012). Second, taking frequent breaks in order to respond to parenting demands or having increased negative attitudes toward added financial, emotional and relationships demands of parenting roles, impedes individuals from positive thinking and decreases attention span towards work tasks (Peeters $e t$ al., 2005). Third, people might lose a considerable amount of their energy by meeting their parenting demands. This can result in diminished work effort, absenteeism, and, in extreme cases, lead to burnout (Anderson et al., 2002). Overall, we propose that parenting stress will increase FWI and this may cause withdrawal from work by decreasing concentration, job loyalty, engagement and task performance. Thus,

$\mathrm{H}_{3}$ : Parenting stress will be positively related with family to work interference for both female and male entrepreneurs. 
Finally, we posit that parenting stress will mediate the relationships between social support and FWI, and between social support and gender stereotypes. Past research found that social support is associated with FWI through decreasing the stressors of family roles (Seiger and Wiese, 2009; Selvarajan et al., 2013). Social support from the community, friends and family, reduces role conflict and provides opportunities to share problems and to learn how others to deal with similar stressors, all of which might reduce FWI (Grzywacz and Marks, 2000). In fact, social support can have a protective role on family to work conflict, especially for individuals who have difficulties in their family lives (Van Daalen et al., 2006). These individuals need more support and extra help in order to decrease their stress levels and, in turn, the level of family to work conflict. Therefore, social support is likely to be a proximal predictor of FWI.

In addition, and as discussed above, traditional gender stereotypes are likely to affect parenting stress, which in turn is associated with FWI. Therefore, it is expected that gendered beliefs would also have impact on FWI indirectly, though the mediating role of parenting stress. In keeping with the effects of gender stereotypes on parenting stress for men and women, this impact would be in negative for females and positive for males.

Although parenthood is the role of both men and women and should be a shared responsibility, women tend to receive strong socialization on parenting and internalize their main role in parenting domain in both traditional and modern societies (Craig and Sawrikar, 2009). On the other hand, for men, a lack of prioritizing the parenting role and a perception that the caring for children is the main role of women, is likely to diminish the FWI (Lyness and Judiesch, 2014).

Along these lines, Fu and Shaffer (2001) found that, in situations where women are perceived as caregiver and have more family roles, these women typically have higher FWI. For example, it has been shown that mothers with internalized gendered-role may be distracted by worries about the parenting demands during working hours therefore suffer in terms of productivity or efficiency at work (Beauregard, 2006). In the specific field of entrepreneurship, McGowan et al., (2012, p. 69) remarked that "Aspects of the entrepreneurial experience prove highly rewarding, whilst others render the journey somewhat trickier for women to travel than for the majority of men, given their tendency to fulfil the majority of caring and home-making roles and associated duties." 
Although the effect is expected to be different for men and women, traditional gender stereotypes are expected to exert a direct influence on parenting stress and an indirect influence on FWI. In other words, traditional gender stereotypes are expected to act as an attitudinal stressor that affect individuals' parenting stress levels, and in turn serve as distal predictors of FWI. Therefore,

$\mathrm{H}_{4 a}$ : Parenting stress will partially mediate the effects of social support on family to work interference for both female and male entrepreneurs.

$\mathrm{H}_{4 b}$ : Parenting stress will partially mediate the effects of gender stereotypes on family to work interference for both female and male entrepreneurs.

\section{Method}

\section{Sample}

This study draws on data from the Household, Income and Labour Dynamics in Australia (HILDA) survey. HILDA is a nationally representative longitudinal household survey initiated in 2001 by the Australian government. The first wave covered 19,914 individuals in 7,682 households. In wave 11 this sample was topped up with an additional 2,153 households and 5,477 individuals. This paper relies on wave 1, 5,8 and 11of the HILDA survey because only these four waves included measures of all variables under consideration in our model.

The sample includes male and female self-employed with parenting responsibilities $(\mathrm{N}=2051)$; we considered all types of entrepreneurs, regardless of whether they had incorporated their business or not. The majority of the respondents (92.3\%) were married and have children aged 15 or younger. The mean age was 47.7 years. The education level varied as follows: $53.5 \%$ of the respondents completed high school, 20.9\% did not complete high school degree, and $25.6 \%$ had a university degree.

\section{Measures}

\section{Social Support}

The measurement of social support was an index of perceived personal support and friendship (Flood, 2005). The survey included ten statements on perceptions of personal support. 
Examples of these items were "I seem to have a lot of friends" and "There is someone who can always cheer me up when I'm down". Respondents were asked to rate their agreement on whether each statement applies to them, on a Likert scale from 1 (strongly disagree) to 7 (strongly agree), with a higher score indicating the perception of a higher degree of support. The internal reliability of the social support measure was very good (Cronbach $\alpha=.81$ ).

\section{Gender Stereotypes}

Gender stereotypes captured a number of shared beliefs about the characteristics and attributes associated with each sex (Gupta et al., 2009). Attitudes to gender roles were measured by using a five-item gender role ideology scale developed by van Egmond et al. (2010). Examples of items included: "It is better for the family if the husband is the principal breadwinner outside the home and the wife has primary responsibility for the home and children" and "If both husband and wife work, they should share equally in the housework and childcare." Responses were collected on a Likert scale from 1 (strongly disagree) to 7 (strongly agree). Individuals with higher scores on these items represent traditional views on gender stereotypes. The gender stereotypes measure was reliable (Cronbach $\alpha=.72$ ).

\section{Parenting stress}

In each year of the HILDA wave, individuals with parenting responsibilities are asked how strongly they agree or disagree with four statements related to parenting stress: "Being a parent is harder than I thought it would be," "I often feel tired, worn out or exhausted from meeting the needs of my children," "I feel trapped by my responsibilities as a parent," and "II find that taking care of my child is much more work than pleasure" (McPherson et al., 2008; Ostberg and Hagekull, 2000). Responses were measured on a Likert scale froml (strongly disagree) to 7 (strongly agree) and higher scores revealed higher parenting stress. The Cronbach $\alpha$ for the parenting stress measure was .75 .

\section{Family to work interference}

The work family strains and gains scale (Marshall and Barnett, 1993) was used to measure the effect of family on work. More specifically, FWI was measured with the four items from that scale: "Because of my family responsibilities, I have to turn down work activities or 
opportunities that I would prefer to take on", "Because of my family responsibilities, the time I spend working is less enjoyable and more pressured", "I worry about what goes on with my children while I am at work", and "Thinking about the children interferes with my performance at work". Responses were measured on a Likert scale from 1 (strongly disagree) to 7 (strongly agree); higher scores indicated high FWI. The Cronbach $\alpha$ for the FWI measure was .71.

\section{Findings}

All relationships in this study were tested with a full structural model, which includes both measurement and structural models. The measurement model was used to analyse the factor structures and the consistency of research constructs, whereas the structural model was used to test the hypotheses. In both the measurement and structural models, a series of multiple-group analyses were conducted to test whether the variables have the same factor structures for both sex groups and whether the structural models are equivalent for men and women. The descriptive statistics, zero-order correlation indices, and reliabilities scores are shown in Table 1.

\section{Measurement Model}

In the measurement model, we sought to determine whether the patterns of factor loadings and the intercorrelations among the factors are invariant across sex. Two models (unconstrained and constrained) relying on maximum likelihood estimation were used to determine whether the measurement model was the same for each sex. While the unconstrained model enabled the measurement of factor loadings and intercorrelations among factors without any restriction, the constrained model set identical values (for factor loadings and intercorrelations among factors) for male and female entrepreneurs.

- Insert Table 1 here -

The results of the measurement model revealed that the loadings of the items were significant and in line with the respective four-factor structure (see Figure 1). This demonstrates that all the latent variables have been measured adequately by the items and lends support for convergent validity among variables (Anderson and Gerbing, 1988). In addition, social support as an independent variable, parenting stress as a mediator and FWI as a dependent variable were 
significantly correlated with each other. These intercorrelations build a case to test the mediating role of parenting stress between social support and FWI.

- Insert Table 2 here -

Three models indicated acceptable $\chi^{2} / \mathrm{df}$ ratio and fit indices (see Table 2 ). In the comparison

of the unconstrained and constrained models, no significant chi-square differences $\left(\Delta \chi^{2}\right)$ were identified, indicating that the model was equivalent across male and female entrepreneurs.

- Insert Figure 1 here -

Table 2 presents a detailed multiple-group comparison of fit indices and indicates that the model in which the value for factor loadings was set to be equal for both sex groups produced a nonsignificant chi-square $\left[\Delta \chi^{2}(\mathrm{df}=16)=19.87, \mathrm{p}=.226(\Delta \mathrm{IFI}=.000 ; \Delta \mathrm{CFI}=-.001 ; \Delta \mathrm{SRMR}=-\right.$ $.001 ; \triangle \mathrm{RMSEA}=-.001)]$. Similarly, the model in which variances and intercorrelations of factors were set to be equal across both sex groups also produced a non-significant chi-square $\left[\Delta \chi^{2}(\mathrm{df}=10)=16.12 ; \mathrm{p}=.092(\Delta \mathrm{IFI}=-.001 ; \Delta \mathrm{CFI}=.000 ; \Delta \mathrm{SRMR}=.001 ; \Delta \mathrm{RMSEA}=\right.$ $.000)]$. Thus, the results indicate that the measurement model is valid and similar for both male and female entrepreneurs.

\section{Structural Model}

Following the measurement tests, we developed a structural model in three phases. First, we conducted a multiple-group comparison within different structural models to determine whether alternative structural models were equivalent for male and female groups or not. Second, as suggested by Baron and Kenny (1986), the mediator's criteria were tested in order to find evidence of the mediating role of parenting stress between independent and dependent variables. Third, we compared the alternative mediator models within each other to find a better structural model.

In order to test alternative structural models across sex groups, both the unconstrained and constrained models were used. Following the same procedure as in the measurement model, the unconstrained model was set without any restriction. Whereas the measurement weight model was set to have equal factor loadings, the structural weight model was set to have equal path coefficient, and, the structural covariance model was similarly set to have equal factor variances 
across male and female entrepreneurs. These freely estimated and constrained models were tested for each of the four alternative structural models.

The results of the four alternative structural models are shown in Table 3 and can be summarized as follows: in Model 1, parenting stress fully mediated the effects of both social support and gender stereotypes on FWI; Model 2 demonstrated partial mediation for both social support and gender stereotypes; Model 3 had partial mediation for social support and full mediation for gender stereotypes; and Model 4 demonstrated full mediation for social support and partial mediation for gender stereotypes.

\section{- Insert Table 3 here -}

The results in Table 3 indicate that there were no significant chi-square differences between sex groups for the alternative models (Model 1, 2, 3, or 4). Thus, the comparison of unconstrained and constrained models revealed that the four alternative structural models were equivalent for male and female entrepreneurs. In addition, contrary to the prediction formulated in $\mathrm{H}_{2 \mathrm{~b}}$, there was no significant difference in the path coefficients of social support to parenting stress and gender stereotypes to parenting stress between male and female entrepreneurs. Therefore, because sex did not produce any significant differences in both the measurement and structural model, data were combined across sex in all of the subsequent analyses.

In the second step, the structural models were tested with the combined data set and the relationship between independent, mediating, and dependent variables were examined. Baron and Kenny (1986) suggested that for a mediation to exist, the path coefficients from independent variables (in our case, social support and gender stereotypes) to mediator (parenting stress) and dependent variables (FWI) must be significant in order to continue to test the mediation effect.

As shown in Figure 2, there was a significant negative relationship $(\beta=-.49 ; \mathrm{p}<.001)$ between social support and parenting stress. $\mathrm{H}_{1}$ is therefore accepted. However, gender stereotypes had no significant relationship $(\beta=.04 ; \mathrm{p}>.05)$ with parenting stress. This leads to the rejection of $\mathrm{H}_{2 \mathrm{a}}$. The results indicate the existence of a possible mediation between social support and FWI, but not between gender stereotypes and FWI. In addition, there was a significant positive relationship $(\beta=.64 ; \mathrm{p}<.001)$ between parenting stress and FWI. $\mathrm{H}_{3}$ is therefore accepted and this suggests that the initial conditions for a mediating role of parenting stress are met. Lastly, 
a significant negative relationship $(\beta=-.50 ; \mathrm{p}<.001)$ between social support and FWI were also found.

- Insert Figure 2 here -

The third and final step was to compare the partially mediated model with the fully mediated model. The results in Table 4 reveal that there is a significant chi-square $\left[\Delta \chi^{2}(\mathrm{df}=1)=18.99\right.$, $\mathrm{p}=.000(\Delta \mathrm{IFI}=.006, \Delta \mathrm{CFI}=.006, \Delta \mathrm{SRMR}=.007, \Delta \mathrm{RMSEA}=.002)]$ between partially and fully mediated models, indicating that the partially mediated model had a better fit for data. Moreover, the path coefficient from social support to FWI was reduced from .50 to .27 when parenting stress was entered into the model, suggesting that the relationship between social support and FWI was partially mediated by parenting stress. $\mathrm{H}_{4 \mathrm{a}}$ is therefore accepted. Importantly, about $25 \%$ of the variance in parenting stress was explained by social support, and about $43 \%$ of the variance in FWI was explained by social support and parenting stress.

- Insert Table 4 here -

However, there was not any significant relationship between gender stereotypes and parenting stress. Similarly, the path coefficient from gender stereotypes to the dependent variable -family to work interference- was not significant. Therefore, the required conditions for a mediation of parenting stress between gender stereotypes and FWI were not satisfied, and $\mathrm{H}_{4 \mathrm{~b}}$ is rejected.

\section{Discussion}

The results of this study address several issues and can be interpreted in terms of the each variables in the model. The findings on social support and parenting stress, which is proposed in $\mathrm{H}_{1}$, demonstrate that social support is negatively related to parenting stress. As suggested by COR theory (Hobfoll, 1989), social support seems to replenish entrepreneurs' personal resources, thereby enabling them to accomplish their work tasks.

Understanding social support as the perception that individuals have of their social network to communicate and share problems might explain its strengthening effect to reduce parenting stress. Social support is related to resilience toward additional demands of parenting by offering trust, friendship and love. It also provides opportunities to share feelings and experiences that are beneficial to coping and adapting to parenting demands. In the context of entrepreneurship, 
however, social support is most likely to be provided by the entrepreneur's personal network rather than from a supervisor and the organisation as proposed in organisational studies (Benjamin and Samson, 2014; ten Brummelhuis et al., 2010).

The second sets of findings indicate that gender stereotyping has no significant relationship with both parenting stress $\left(\mathrm{H}_{2 \mathrm{a}}\right)$ and FWI and that this holds true for both male and female entrepreneurs $\left(\mathrm{H}_{2 b}\right)$. One reason for this absence of influence is that a series of child-related factors (age, social skills, and problem behaviours) and other contextual factors (family structure, conflict, education, and income) may affect parenting stress (Abidin, 1995) and, indirectly, FWI.

Another reason could be that, as suggested by social role theory, gendered stereotypes are learned by women and men and that this defines their roles over time. They shape and define individual skills and performances over the long term and are located by default in an individual's cognition process (Bourne and Calas, 2013). Internalization of gender stereotypes and behaving in such a manner reduces the possibility of failure and links to successful role performance (Vogel et al., 2003). Behaving consistently with social perceptions is easier and less risky than behaving contrary to expectations (Hibbard and Buhrmester, 1998). In our context, stereotypical gender beliefs did not have a stressor role in parenting and FWI for both male and female entrepreneurs.

The other important finding revealed that entrepreneurs who scored high in parenting stress perceived more FWI $\left(\mathrm{H}_{3}\right)$. The stress related to the perception of low competence in parenting roles or low responsiveness to parenting demands may lead to an imbalance between family and work life, and interference from family to work. Stressful parenting experiences have been shown to directly correlate with negative spillover of family to work life (ten Brummelhuis et al., 2010). Experience of difficulties, stress and having negative perceptions of parenting demands often results in time pressure, energy shortage and pessimistic thinking; which in turn may affect work outcomes and lead to family life interfering with work. Individuals with high parenting stress tend to feel cynical, lack time and energy, and have diminished concentration at work. The effects of low capability and dissatisfaction on parenting roles would decrease motivation and self-efficacy at work, which in turn, may increase absenteeism, job dissatisfaction and burnout. 
The final finding was the partially mediating role of parenting stress on the relationship between social support and FWI $\left(\mathrm{H}_{4 a}\right)$. Specifically, these results suggest that social support has both a direct effect on FWI and an indirect effect through parenting stress. This finding is in line with past researches, which found evidence of the negative direct relationship between social support and family-work conflict (Selvarajan et al., 2013). Social support experienced by individuals leads to more possibilities to discuss problems and obtain feedback within the family domain. As a result, parenting demands are addressed more effectively, which leads in turn to a reduction of interference from family to work. These findings also demonstrated that social support predicts and shapes the perceptions of parenting and the interpretation of parenting demands in a positive way that can reduce FWI.

\section{Conclusion}

The findings of the current study should be of interest not only to researchers, but also to policy makers, entrepreneurs, families and parents. The comprehensive and detailed approach to unstudied domain of entrepreneurship, which is family lives and parenting, helps to better understand entrepreneurs and the roles that they have to undertake. This section addresses the contributions to entrepreneurship research field, policy, and practice and presents the limitations with suggestions to future studies.

\section{Implications for entrepreneurship research}

This study attempts to extend previous work on parenting and vocational behaviour by investigating the perceptional and stereotypical antecedents of parenting stress and examining the impact of parenting stress on family to work interference. Although entrepreneurship has often been perceived as a viable career path to decrease work family conflicts, starting a business should not be viewed as an easy alternative to employment with ample time for long lunches, 'sleep ins' and late starts to the day (Parasuraman and Simmers, 2001; Seva and Öun, 2015). In addition to the challenges of parenting, many entrepreneurs work long hours and face constant pressure to achieve a positive return in their business venture. Therefore, a better understanding of entrepreneurs' parenting stress can shed some light on the challenges faced by self-employed individuals and contributes to the vocational behaviour and career development 
literature. In addition, this study moves beyond the direct effects of social support on familywork balance. In doing so, we consider how social support influences FWI through parenting stress in more complex ways than was previously hypothesized.

In addition to the dearth of conceptual and empirical research on entrepreneurs' family experiences and challenges, family issues have rarely been investigated in the entrepreneurship context. The traditional focus on work-specific factors (such as job demand, job control, and flexible working hours) and social capital (e.g. friends, alumni network, start-up team) factors to explain entrepreneurial performance fails to recognize the work-family impact in entrepreneurship and specifically the parenting roles. This study provides empirical evidence of the importance parenting stress on FWI for both men and women entrepreneurs.

Lastly, this study highlighted the idea of considering entrepreneurs as members of society. Although gender stereotypes were not found to be statistically significant predictors of parenting stress, they can have different implications in different social context. It is important to note that entrepreneurship is not a separate construct from society, but an aspect of the society as a whole.

\section{Implications for policy and practice}

The balance between individuals' work and family life is an important subject for families today. This study revealed the growing need to address the issue of parenting stress, as an increasing number of people set up their own business to accommodate professional goals alongside personal responsibilities. The findings revealed that social support is a critical factor, which can reduce parenting stress and FWI.

Established entrepreneurs facing difficulties in meeting the conflicting demands of their family and job are likely to find effective resources among their family members, friends and community. Social networks can provide direct resources (e.g., a family member provides childcare assistance to an overworked parent) and indirect coping resources (e.g., a friend helps a parent to see a stressful situation from a different, less distressing perspective). Similarly, would-be entrepreneurs are advised to carefully map their social networks and to identify the help they can receive from their family and friends when they will inevitably face challenging situations in establishing and growing their business venture. 
Perhaps one of the most crucial sources of social support is the partner or spouse of the entrepreneur. People with parental responsibilities who embark on the entrepreneurship journey should not only work on their business plan but also prepare a "social contract" with their significant other or spouse. They need to be aware that entrepreneurial life is a tornado of long hours, high risk and uncertainty. Recognising these challenges and developing strategies to mitigate associated risks are likely to diminish stress when difficulties arise.

While family and friends are the main fabric of social support, policies that develop social support in the community can help too. These policies include assisting men and women with their parenting responsibilities and offering support with counselling agencies or parenthood education programs. Supporting parents with educational, communication-training or stress management programs can facilitate better relationships with their children and they would more likely perceive themselves as adequate parents, thereby reducing parenting stress. In addition, the development of child-care facilities can free up some time for parent-entrepreneurs and help them balance work and family demands (James, 2014). A reduction of parenting stress and FWI will enrich work outcomes, including job dedication, job satisfaction, career success, and the overall performance of enterprises, which is beneficial for the economy in the longterm.

\section{Limitations and suggestions for future research}

The results of this study should be considered in light of its limitations. The first limitation of the study concerns the data collection methodology. The data of this research rely on self-reports of the entrepreneurs, suggesting the possibility that results may be due to method bias or, possibly, a generalized tendency to responding a particular way. While the results of this study might have been affected by method bias, there are several reasons to place some confidence in the results. First, the theory-based nature of the hypothesized model and its fit to the empirical data provide considerable confidence that the present findings are not due to chance. Second, the results indicated those participants' perceptions of social support and their gender stereotypes were significantly different from each other. Also, the measurement model revealed a good fit with the four factors: this reduces concerns about common method bias. 
The second limitation concerns generalization of the tested model. In this study, FWI is considered as an outcome of parenting stress and social support alone. However, future studies may include the role of various factors such as core values, personality or the degree of satisfaction with the partner as predictor variables. For the unexplained part of the variance in parenting stress and FWI, researchers may also obtain a more comprehensive model by investigating some other mediating or moderating effects.

Third, the effect of time and the changes in business and social environment over time was not tested. Further longitudinal and/or experimental studies would enable the researchers to control

for other influential variables over years and test the causality between variables more precisely. In addition, future longitudinal studies may explore the relations at the intra-individual level.

Finally, the study's model was tested in the specific setting of Australia, which limits the generalization of the model. A replication of this study in other settings will help produce reliable indicators and improve the validity of constructs.

\section{References}

Abidin, R.R. (1995). Parenting Stress Index: Professional Manual (3rd ed.), Odessa, FL: Psychological Assessment Resources Inc.

Ahl, H. (2006), "Why research on women entrepreneurs needs new directions", Entrepreneurship Theory and Practice, Vol. 30 No. 5, pp. 595-621.

Anderson, J.C. and Gerbing, D.W. (1988), "Structural equation modelling in practice: A review and recommended two-step approach", Psychological Bulletin, Vol. 103 No. 3, pp. 411-423.

Anderson, S.E., Coffey, B.S. and Byerly, R.T. (2002), "Formal organizational initiatives and informal workplace practices: Links to work-family conflict and job-related outcomes", Journal of Management, Vol. 28 No. 6, pp. 787-810.

Baron, R.M. and Kenny, D.A. (1986), “The moderator-mediator variable distinction in social psychological research: Conceptual, strategic, and statistical considerations", Journal of Personality and Social Psychology, Vol. 51 No. 6, pp. 1173-1182. 
Beauregard, T.A. (2006), "Predicting interference between work and home: A comparison of dispositional and situational antecedents", Journal of Managerial Psychology, Vol. 21 No. 3, pp. 244-264.

Benjamin, O.A. and Samson, B.S. (2014), "The impact of demographic factors on family interference with work and work interference with family and life satisfaction", International Journal of Humanities and Social Science Invention, Vol. 3 No. 4, pp. 31-38.

Berkman, L. F., Glass, T., Brissette, I., and Seeman, T. E. (2000), "From social integration to health: Durkheim in the new millennium", Social Science \& Medicine, Vol. 51 No. 6, pp. 843857.

Boden, R. (1996), “Gender and self-employment selection: An empirical assessment”, Journal of Socio-Economics, Vol. 25 No. 6, pp. 671-682.

Bokhorst, C. L., Sumter, S. R., and Westenberg, P. M. (2010), "Social support from parents, friends, classmates, and teachers in children and adolescents aged 9 to 18 years: Who is perceived as most supportive?" Social Development, Vol.19 No. 2, pp. 417-426.

Bourne, K.A. and Calas, M.B. (2013), "Becoming 'real' entrepreneurs: Women and the gendered normalization of 'work", Gender, Work and Organization, Vol. 20 No. 4, pp. 425438 .

Canty-Mitchell, J. and Zimet, G.D. (2000), "Psychometric properties of the multidimensional scale of perceived social support in urban adolescents", American Journal of Community Psychology, Vol. 28 No. 3, pp. 391-400.

Cobb, S. (1976), "Social support as a moderator of life stress", Psychosomatic Medicine, Vol. 38 No. 5, pp. 300-314.

Cooper, C.E., McLanahan, S.S., Meadows, S.O., and Brooks-Gunn, J. (2009), "Family structure transitions and maternal parenting stress", Journal of Marriage and Family, Vol. 71 No. 3, pp. 558-574.

Craig, L. (2006), "Children and the revolution: A time-diary analysis of the impact of motherhood on daily workload", Journal of Sociology, Vol. 42 No. 2, pp. 125-143. 
Craig, L. and Sawrikar, P. (2009), "Work and Family: How does the (gender) balance change as children grow?", Gender, Work and Organization, Vol. 16 No. 6, pp. 684-709.

Cuddy, A.J.C., Fiske S.T. and Glick, P. (2004), "When professionals become mothers, warmth doesn't cut the ice", Journal of Social Issues, Vol. 60 No. 4, pp. 701-709.

Davidson, M.J., Fielden, S. L. and Omar, A. (2010), "Black, Asian and minority ethnic female business owners: discrimination and social support", International Journal of Entrepreneurial Behaviour \& Research, Vol. 16 No. 1, pp. 58-80.

Deater-Deckard, K. (2005), "Parenting stress and children's development: Introduction to the special issue", Infant and Child Development, Vol. 14 No. 2, pp. 111-115.

Eagly, A. H. (1997), "Sex differences in social behaviour: Comparing social role theory and evolutionary psychology”, American Psychologist, Vol. 52 No. 12, pp. 1380- 1383.

Eagly, A. H., Wood, W., and Diekman, A. B. (2000), "Social role theory of sex differences and similarities: A current appraisal", in Eckes, E, and Trautner, M. H. (Eds.), The Developmental Social Psychology of Gender, Psychology Press, New York, pp. 123-174.

Eby, L.T., Casper, W.J., Lockwood, A., Bordeaux, C. and Brinley, A. (2005), "Work and family research in IO/OB: Content analysis and review of the literature (1980-2002)", Journal of Vocational Behaviour, Vol. 66 No. 1, pp. 124-197.

Erickson, R.J., Nichols, L. and Ritter, C. (2000), "Family influences on absenteeism: Testing an expanded process model", Journal of Vocational Behaviour, Vol. 57 No. 2, pp. 246-272.

Flood, M. (2005), “Mapping loneliness in Australia”. The Australia Institute, Discussion Paper, No: 76.

Frone, M.R., Russell, M., and Cooper, M.L. (1992), “Antecedents and outcomes of work-family conflict: Testing a model of the work-family interface", Journal of Applied Psychology, Vol. 77 No. 1, pp. 65-78.

Fu, C.K. and Shaffer, M.A. (2001), "The tug of work and family: Direct and indirect domainspecific determinants of work-family conflict", Personal Review, Vol. 30 No. 5, pp. 502-522. 
Grönlund, A. (2007), “More control, less conflict? Job demand-control, gender and work family conflict", Gender, Work and Organization, Vol. 14 No. 5, pp. 476-496.

Grzywacz, J. G. and Marks, N. F. (2000), "Reconceptualizing the work-family interface: An ecological perspective on the correlates of positive and negative spillover between work and family", Journal of Occupational Health Psychology, Vol. 5 No. 1, pp. 111-126.

Gupta, V., Turban, D., Wasti, A. and Sikdar, A. (2009), "The role of gender stereotypes in perceptions of entrepreneurs and intentions to become an entrepreneur", Entrepreneurship Theory and Practice, Vol. 33 No. 2, pp. 397-417.

Hamilton, D.L., and Sherman, J.W. (2014), "Stereotypes", in Wyer, Jr.R.S. and Srull T.K. (Eds.), Handbook of Social Cognition (2nd ed.): Vol. 2, Applications, 1-68. Hillsdale, NJ: Erlbaum, pp. 1-68.

Hastings, R.P. (2002), "Parental stress and behaviour problems of children with developmental disability", Journal of Intellectual \& Development Disability, Vol. 27 No. 3, pp. 149-160.

Heilman, M.E. (2001), "Description and prescription: How gender stereotypes prevent women's ascent up the organizational ladder", Journal of Social Issues, Vol. 57 No. 4, pp. 657674.

Heilman, M.E. and Chen, J.J. (2003), "Entrepreneurship as a solution: the allure of selfemployment for women and minorities", Human Resource Management Review, Vol. 13 No. 2, pp. 347-364.

Hetherington, E. M. (2014), Coping with divorce, single parenting, and remarriage: A risk and resiliency perspective, Psychology Press.

Hibbard, D.R. and Buhrmester, D. (1998), “The role of peers in the socialization of genderrelated social interaction styles", Sex Roles, Vol. 39 No. 3, pp. 185-202.

Hobfoll, S. E. (1989), "Conservation of resources: A new attempt at conceptualizing stress”, American Psychologist, Vol. 44, pp. 513-524. 
Hobfoll, S. E. (2002), "Social and psychological resources and adaptation", Review of General Psychology, Vol. 6, pp. 307-324.

Huang, C. Y., Costeines, J., Kaufman, J. S., and Ayala, C. (2014), "Parenting stress, social support, and depression for ethnic minority adolescent mothers: impact on child development", Journal of Child and Family Studies, Vol. 23 No. 2, pp. 255-262.

James, Al. (2014), "Work-life 'balance', recession and the gendered limits to learning and innovation (Or, Why it pays employers to care)", Gender, Work and Organization, Vol. 21 No. 3, pp. 273-294.

Johnston, C. and Mash, E. J. (2001), "Families of children with attention deficit/hyperactivity disorder: Review and recommendations for future research", Clinical Child and Family Psychology Review, Vol. 4 No. 3, pp. 183-207.

Kelloway, E.K., Gottlieb, B.H. and Barham, L. (1999), "The source, nature, and direction of work and family conflict: A longitudinal investigation", Journal of Occupational Health Psychology, Vol. 4 No. 4, pp. 337-346.

Kirkwood, J. and Tootell, B. (2008), "Is entrepreneurship the answer to achieving work family balance?", Journal of Management \& Organization, Vol. 14 No. 3, pp. 285-302.

Koeske, Gary F. and Daimon Koeske, R. (1990), "The buffering effect of social support on parental stress", American Journal of Orthopsychiatry, Vol. 60 No. 3, pp. 440-451.

Lin, N., Dean, A., and Ensel, W. M. (2013), Social support, life events, and depression, Academic Press.

Lindsey, L. L. (2015), Gender roles: A sociological perspective. Routledge Press.

Locke, A., and Yarwood, G. (2017), "Exploring the depths of gender, parenting and 'work': critical discursive psychology and the 'missing voices' of involved fatherhood", Community, Work \& Family, Vol.20 No.1, pp. 4-18.

Lombard, K. (2001), "Female self-employment and demand for flexible nonstandard work schedules", Economic Inquiry, Vol. 39 No. 2, pp. 214-237. 
Loscocco, K.A. (1997), "Work-family linkages among self-employed women and men", Journal of Vocational Behaviour, Vol. 50 No. 2, pp. 204-226.

Louie, A. D., and Cromer, L. D. (2014) "Parent-child attachment during the deployment cycle: Impact on reintegration parenting stress", Professional Psychology: Research and Practice, Vol. 45 No. 6, pp. 496-503.

Lyness, K.S. and Judiesch, M.K. (2014), “Gender egalitarianism and work-life balance for managers: Multisource perspectives in 36 countries", Applied Psychology: An International Review, Vol. 63 No. 1, pp. 96-129.

Marshall, N.L. and Barnett, R.C. (1993), "Work-family strains and gains among two earner couples", Journal of Community Psychology, Vol. 21 No. 1, pp. 64-78.

McGowan, P., Redeker, C.L., Cooper, S.Y. and Greenan, K. (2012), “Female entrepreneurship and the management of business and domestic roles: Motivations, expectations and realities", Entrepreneurship \& Regional Development, Vol. 24 No. 1-2, pp. 53-72.

McPherson, A.V., Lewis, K.M., Lynn, E.A., Haskett M.E. and Behrend, T.S. (2008), "Predictors of parenting stress for abusive and non-abusive mothers", Journal of Child and Family Studies, Vol. 18 No. 1, pp. 61-69.

Mesmer-Magnus, J. and Viswesvaran, C. (2005), "Convergence between measures of work-to family and family-to-work conflict: A meta-analytic examination", Journal of Vocational Behaviour, Vol. 67 No. 2, pp. 215-232

Ostberg, M. and Hagekull, B. (2000), "A structural modelling approach to the understanding of parenting stress", Journal of Clinical Child Psychology, Vol. 29 No. 4, pp. 615-625.

Parasuraman, S. and Simmers, C.A. (2001), "Type of employment, work-family conflicts and well-being: A comparative study", Journal of Organizational Behaviour, Vol. 22 No. 5, pp. 551-568.

Peeters, M.C.W., Montgomery, A.J., Bakker, A.B. and Schaufeli, W.B. (2005), "Balancing work and home: How job demands and home demands are related to burnout", International Journal of Stress Management, Vol. 12 No. 1, pp. 43-61. 
Pierce, G. R., Lakey, B., and Sarason, I. G. (2013), Sourcebook of social support and personality, Springer Science \& Business Media.

Piko, B. (2000), "Perceived social support from parents and peers: which is the stronger predictor of adolescent substance use?" Substance Use \& Misuse, Vol. 35 No. 4, pp. 617-630.

Powell, D.R. (1980), "Personal social networks as a focus for primary prevention of child maltreatment", Infant Mental Health Journal, Vol. 1 No. 4, pp. 232-239.

Powell, G.N., Butterfield, D.A. and Parent, J.D. (2002), “Gender and managerial stereotypes: Have the times changed?", Journal of Management, Vol. 28 No. 2, pp. 177-193.

Powell, G.N. and Graves, L.M. (2003), Women and Men in Management, Thousand Oaks, CA: Sage.

Raikes, H.A. and Thompson, R.A. (2005), "Efficacy and social support as predictors of parenting stress among families in poverty", Infant Mental Health Journal, Vol. 26 No. 3, pp. 177-190.

Seiger, C.P. and Wiese, B.S. (2009), "Social support from work and family domains as an antecedent or moderator of work-family conflicts?", Journal of Vocational Behaviour, Vol. 75 No. 1, pp. 26-37.

Selvarajan, T.T., Cloninger, P.A., and Singh, B. (2013), "Social support and work family conflict: A test of an indirect effects model", Journal of Vocational Behaviour, Vol. 83 No. 3, pp. 486-499.

Seva, I. J. and Öun, I. (2015), "Self-employment as a strategy for dealing with the competing demands of work and family? The importance of family/lifestyle motives", Gender, Work and Organization, Vol. 22 No. 3, pp. 256-272.

Shimazu, A., Bakker, A.B., and Demerouti, E. (2009), "How job demands affect an intimate partners: A test of the spillover-crossover model in Japan", Journal of Occupational Health, Vol. 51 No. 3, pp. 239-248. 
Stoner, C.R., Hartman, R.I. and Arora, R. (1990), "Work-home role conflict in female owners of small businesses: An exploratory study", Journal of Small Business Management, Vol. 28, No. 1, pp. 30-38.

Taylor, Z. E., Conger, R. D., Robins, R. W., and Widaman, K. F. (2015), "Parenting practices and perceived social support: Longitudinal relations with the social competence of Mexicanorigin children", Journal of Latina/o Psychology, Vol. 3 No. 4, pp. 193-208.

ten Brummelhuis, L.L., Bakker, A.B. and Euwema, M.C. (2010), "Is family-to-work interference related to co-workers' work outcomes?", Journal of Vocational Behaviour, Vol. 77 No. 3, pp. 461-469.

ten Brummelhuis, L.L., Oosterwaal, A. and Bakker, A.B. (2012), “Managing family demands in teams: The role of social support at work", Group \& Organization Management, Vol. 37 No. 3, pp. 376-403.

Thomason, E., Volling, B. L., Flynn, H. A., McDonough, S. C., Marcus, S. M., Lopez, J. F., and Vazquez, D. M. (2014), "Parenting stress and depressive symptoms in postpartum mothers: Bidirectional or unidirectional effects?" Infant Behaviour and Development, Vol. 37 No.3, pp. 406-415.

Thompson, C. A., and Prottas, D. J. (2006), "Relationships among organizational family support, job autonomy, perceived control, and employee well-being", Journal of Occupational Health Psychology, Vol. 11 No.1, pp.100-118.

Tull, E.S., Sheu, Y.T., Butler, C. and Cornelious, K. (2005), "Relationships between perceived stress, coping behaviour and cortisol secretion in women with high and low levels of internalized racism", Journal of the National Medical Association, Vol. 97 No. 2, pp. 206-212.

Van Daalen, G., Willemsen, T.M. and Sanders, K. (2006), "Reducing work-family conflict through different sources of social support", Journal of Vocational Behaviour, Vol. 69 No. 3, pp. 462-476. 
Van Egmond, M., Baxter, J., Buchler, S. and Western, M. (2010), “A stalled revolution? Gender role attitudes in Australia 1986-2005", Journal of Population Research, Vol. 27 No. 3, pp. 147168.

Vogel, D.L., Wester, S.R., Heesacker, M., and Madon, S. (2003), "Confirming gender stereotypes: A social role perspective", Sex Roles, Vol. 48 No. 11, pp. 519-528.

Wallece, J.E. (2014), "Gender and supportive co-worker relations in the medical professions", Gender, Work and Organizations, Vol. 21 No.1, pp. 1-17.

Walsh, J. (2013), "Gender, the work-life interface and well-being: A study of hospital doctors", Gender, Work and Organization, Vol. 20 No. 4, pp. 439-453.

Zhu, F., Burmeister-Lamp, K. and Hsu, D. K. (2017). "To leave or not? The impact of family support and cognitive appraisals on venture exit intention." International Journal of Entrepreneurial Behaviour \& Research, Vol. 23 No. 3, pp. 566-590. 
Table I. Descriptive statistics of variables of interest

\begin{tabular}{lccccccc}
\hline Variables & 1 & 2 & 3 & 4 & Mean & SD & \multicolumn{2}{c}{ Cronbach's } \\
\hline 1. Social support & 1 & & & & 5.34 & 1.04 & .81 \\
2. Gender stereotypes & $-.059^{*}$ & 1 & & & 3.43 & 1.18 & .72 \\
3. Parenting stress & $-.300^{* *}$ & $.055^{*}$ & 1 & & 3.37 & 1.24 & .75 \\
4. Family to work interference & $-.310^{* *}$ & $-.110^{*}$ & $.427^{* *}$ & 1 & 3.19 & 1.23 & .71 \\
\hline
\end{tabular}

Notes: SD: Standard Deviation. $\mathrm{N}=2051,{ }^{*} p<.05,{ }^{* *} p<.01$

Table II. Fit indices for measurement model and multiple-group comparison for sex differences

\begin{tabular}{llllllll}
\hline Models & $\chi^{2}$ & $\mathrm{df}$ & IFI & CFI & SRMR & RMSEA & $\Delta \chi^{2}(\mathrm{df})$ \\
\hline Unconstrained Model & 843.56 & 316 & .955 & .955 & .041 & .029 & \\
Measurement Weight Model & 863.43 & 332 & .955 & .954 & .040 & .028 & $19.87(16)$ \\
Structural Covariance Model & 879.55 & 342 & .954 & .954 & .041 & .028 & $16.12(10)$
\end{tabular}

Notes: $\mathrm{N}=2051 . \chi^{2}=$ Chi-square; $\mathrm{df}=$ Degrees of freedom; IFI = Incremental fit index; $\mathrm{CFI}=$ Comparative fit index; SRMR= Standardized root-mean-square residual; RMSEA= Root-mean-square error of approximation. ${ }^{*} p<.05,{ }^{* *} p<.01$ 
Table III. Fit indices for structural models and multiple-group comparison for sex differences

\begin{tabular}{|c|c|c|c|c|c|c|c|}
\hline Models & $\chi^{2}$ & $\mathrm{df}$ & IFI & CFI & SRMR & RMSEA & $\Delta \chi_{2}(\mathrm{df})$ \\
\hline \multicolumn{8}{|l|}{ Model 1} \\
\hline Unconstrained Model & 913.40 & 322 & .950 & .950 & .049 & .030 & \\
\hline Measurement Weight Model & 933.91 & 338 & .949 & .950 & .049 & .029 & $20.51(16)$ \\
\hline Structural Weight Model & 938.97 & 341 & .949 & .950 & .049 & .029 & $5.06(3)$ \\
\hline Structural Covariance Model & 942.08 & 343 & .949 & .950 & .049 & .029 & $3.11(2)$ \\
\hline \multicolumn{8}{|l|}{ Model 2} \\
\hline Unconstrained Model & 849.71 & 318 & .955 & .954 & .044 & .029 & \\
\hline Measurement Weight Model & 869.17 & 334 & .954 & .954 & .044 & .028 & $19.46(16)$ \\
\hline Structural Weight Model & 878.36 & 339 & .954 & .954 & .045 & .028 & $9.19(5)$ \\
\hline Structural Covariance Model & 881.79 & 341 & .954 & .954 & .045 & .028 & $3.43(2)$ \\
\hline \multicolumn{8}{|l|}{ Model 3} \\
\hline Unconstrained Model & 854.17 & 320 & .954 & .954 & .046 & .029 & \\
\hline Measurement Weight Model & 874.40 & 336 & .954 & .954 & .046 & .028 & $20.23(16)$ \\
\hline Structural Weight Model & 880.45 & 340 & .954 & .954 & .046 & .028 & $6.05(4)$ \\
\hline Structural Covariance Model & 883.32 & 342 & .954 & .954 & .046 & .028 & $2.87(2)$ \\
\hline \multicolumn{8}{|l|}{ Model 4} \\
\hline Unconstrained Model & 908.23 & 320 & .950 & .950 & .048 & .030 & \\
\hline Measurement Weight Model & 927.61 & 336 & .949 & .950 & .048 & .029 & $19.38(16)$ \\
\hline Structural Weight Model & 936.17 & 340 & .949 & .950 & .048 & .029 & $8.56(4)$ \\
\hline Structural Covariance Model & 939.34 & 342 & .949 & .950 & .048 & .029 & $3.17(2)$ \\
\hline
\end{tabular}

Table IV. Fit indices among different structural models

\begin{tabular}{llllllll}
\hline Models & $\chi^{2}$ & $\mathrm{df}$ & IFI & CFI & SRMR & RMSEA & $\Delta \chi_{2}(\mathrm{df})$ \\
\hline Partially-Mediated Model & 229.94 & 83 & .951 & .951 & .039 & .042 & \\
Fully-Mediated Model & 248.93 & 84 & .945 & .945 & .046 & .044 & $18.99(1)^{* *}$
\end{tabular}

Notes: $\mathrm{N}=2051 \cdot \chi^{2}=$ Chi-square; $\mathrm{df}=$ Degrees of freedom; IFI = Incremental fit index; $\mathrm{CFI}=$ Comparative fit index; SRMR $=$ Standardized root-mean-square residual; RMSEA $=$ Root-mean-square error of approximation; ${ }^{*} p<.05,{ }^{* *} p<.01$ 
Figure 1. The measurement model

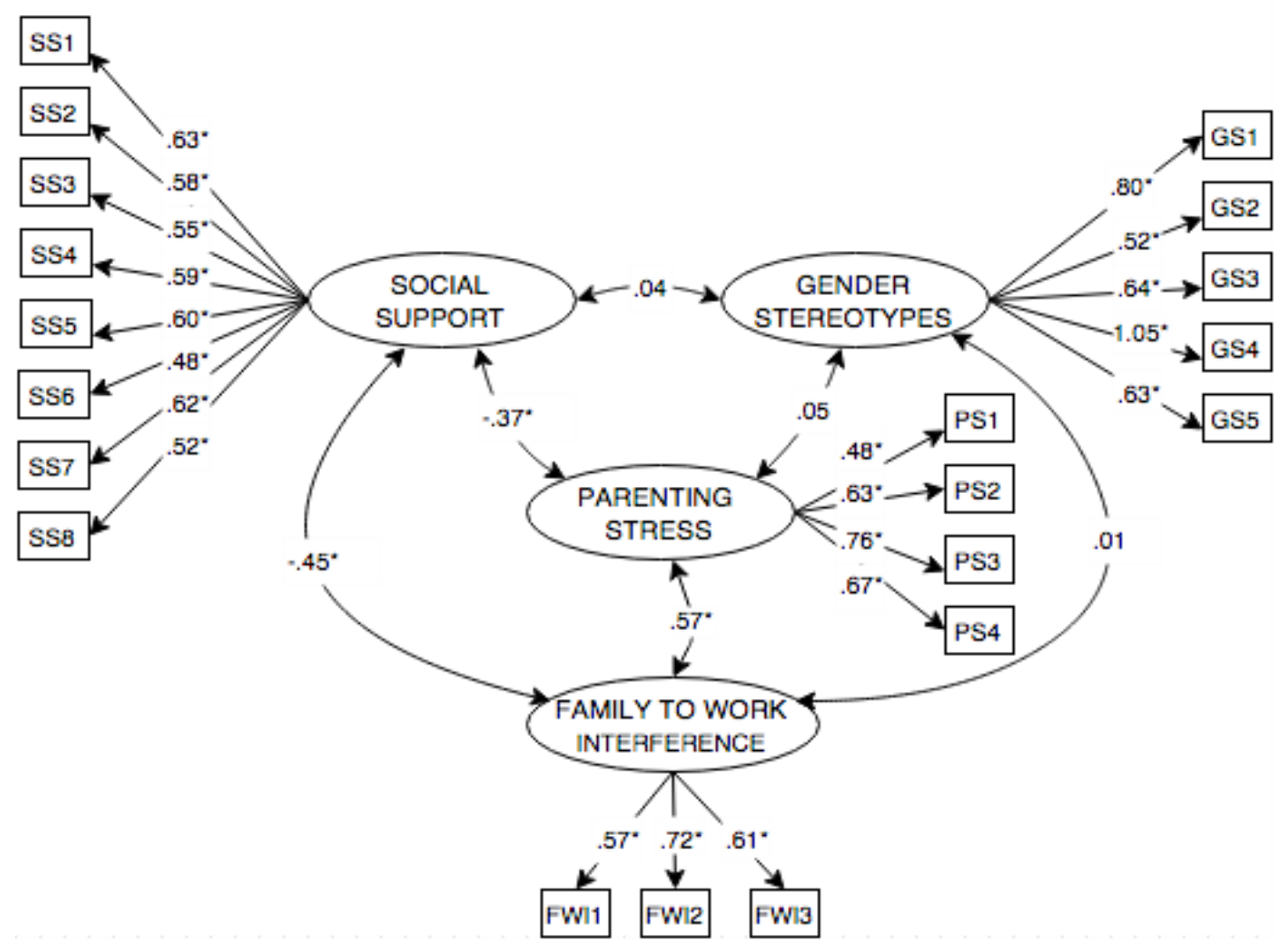

Notes: $\mathrm{N}=2051 .{ }^{*} \mathrm{p}<.01$. SS1-SS8= Eight items from social support scale. GS1-GS5= Five items from gender stereotype scale. PS1-PS4= Four items from parenting stress scale. FWI1-FWI3= Three items from family to work interference scale. 
Figure 2. Structural model

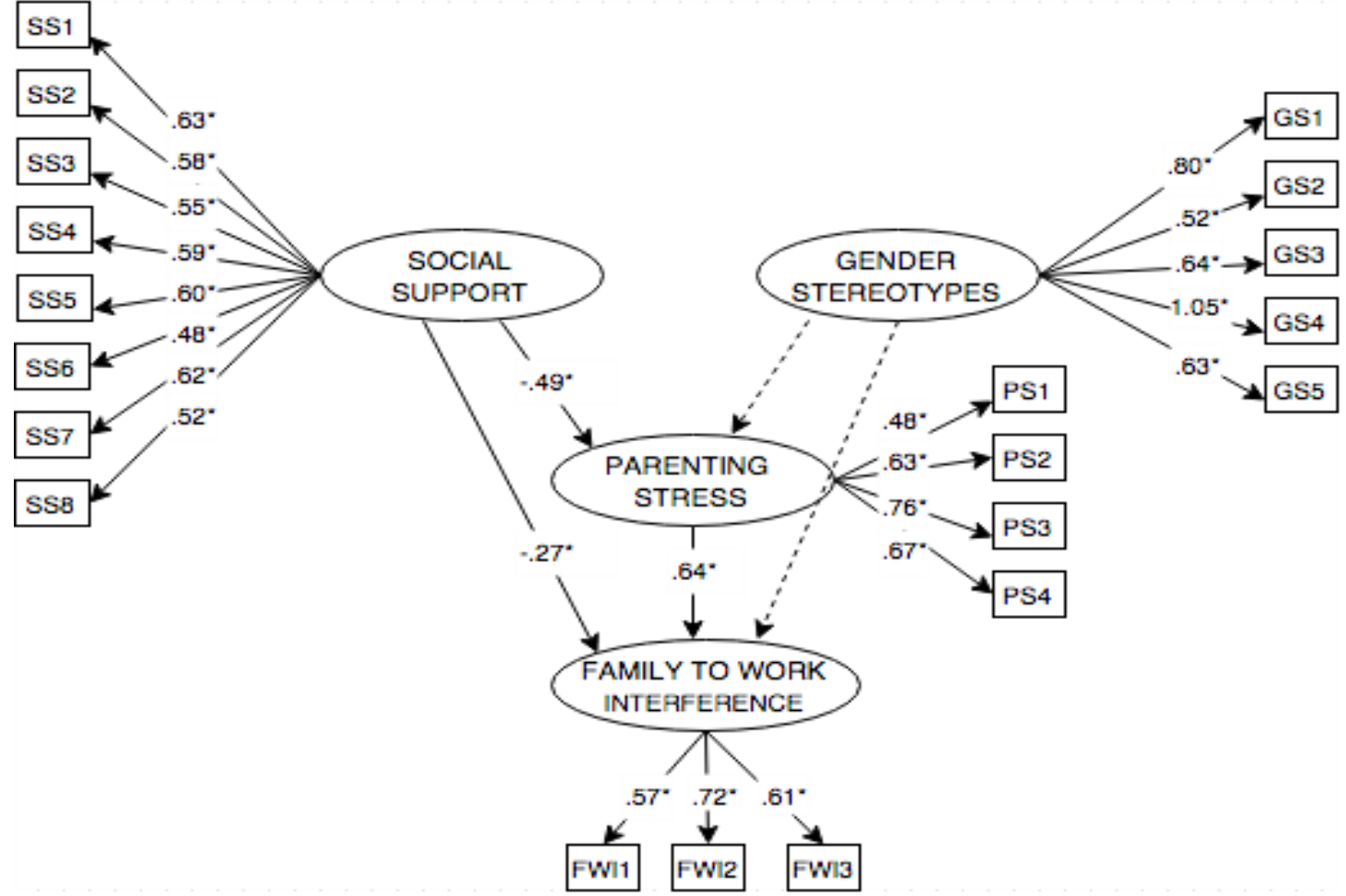

Notes: $\mathrm{N}=2051 .{ }^{*} \mathrm{p}<.01$. SS1-SS8= Eight items from social support scale. GS1-GS5=Five items from gender stereotype scale. PS1-PS4= Four items from parenting stress scale. FWI1-FWI3= Three items from family to work interference scale. 